\title{
РОЛЬ МЕТРОЛОГИЧЕСКОЙ
} ЭКСПЕРТИЗЫ ТЕХНИЧЕСКОЙ ДОКУМЕНТАЦИИ

Ключевые слова: метрологическая экспертиза, нормоконтроль, конструкторская и технологическая документация, CADсистемы

\section{В ПОВЫШЕНИИ КАЧЕСТВА ВЫПУСКАЕМЫХ ИЗДЕЛИЙ}

\author{
Елена ЗИМИНА, Валентина КАЙНОВА
}

Представлены базовые принципы метрологической экспертизы конструкторской и технологической документации. Показана необходимость создания единой информационной среды между системами «конструктор», «технолог», «метролог» в рамках единого информационного пространства промышленности России.

Принципиально важным новым положением Федерального закона РФ «Об обеспечении единства измерений» (№ 102-Ф3 от 26.06.2008 г.) является включение в него ст. 14, содержащей ряд положений, регламентирующих проведение метрологической экспертизы проектной, конструкторской и технологической документации, а также других объектов [1]. Метрологическая экспертиза и нормоконтроль являются частью комплекса работ по метрологическому и нормативному обеспечению проектирования и неотъемлемой частью технической экспертизы конструкторской, технологической, проектной, нормативной и другой документации.

Конструкторская и технологическая документация - значимый и ответственный вид интеллектуальной продукции. В технической документации (ТД) отражаются требования к продукции, такие как потребительские, эксплуатационные, эргономические, надежности, безопасности и др.

В то же время практика подтверждает, что в конструкторской документации обнаруживается порядка $10 \%$ конструкторских (исполнительских) ошибок и 90\% - ошибок, связанных с несоблюдением стандартов и метрологических норм. В ЕСКД предусмотрены конструкторский, технологический и нормоконтроль качества КД $[2,3]$.

Обычно, чем раньше возникает дефект Кд, тем труднее его выявить и тем больший суммарный ущерб он наносит. Эффективность контроля качества конструкторской документации (КД) на этапе ее разработки составляет $46 \%$, на этапе опытного производства - $63 \%$, на этапе серийного производства $-80 \%$, а в процессе эксплуатации доходит до $100 \%$. Следовательно, необходимо уделять особое внимание именно этапу разработки Кд.

Метрологическая экспертиза (МЭ) - анализ и оценка правильности установления и соблюдения метрологических требований применительно к объекту, подвергаемому экспертизе [1]. МЭ проводится в обязательном и добровольном порядке. Она пронизывает все стадии разработки документации продукции машиностроения и является важным элементом системы менеджмента качества метрологического обеспечения. Задачи МЭ успешно решаются при условии ее проведения с ранних стадий разработки документации, начиная с технического задания и разработки технического проекта. Метрологическая экспертиза и нормоконтроль способствуют квалифицированному решению технико-экономических задач при разработке документации.

МЭ ТД проводят путем анализа и оценивания технических решений в части метрологического обеспечения (технических решений, касающихся измеряемых параметров, установления требований к точности измерений, выбора методов и средств измерений, их метрологического обслуживания) [4]. Общие вопросы, решаемые при выполнении метрологической экспертизы:

$\rightarrow$ правильность использования метрологических терминов, наименований измеряемых величин и обозначений их единиц;

$\rightarrow$ правильность обозначения единиц физических величин; 
$\rightarrow$ рациональный выбор номенклатуры измеряемых параметров;

$\rightarrow$ правильность задания норм точности и определение оптимальной точности измерений;

$\rightarrow$ оценка контролепригодности изделия, выбор методов и средств измерения;

$\rightarrow$ оценка экономических параметров по трудоемкости контрольных операций и себестоимости применяемых средств измерений и контролируемых изделий. Метрологическая экспертиза включает в себя метрологический контроль технической документации, который предусматривает проверку документации в процессе ее разработки на соответствие конкретным метрологическим требованиям. Метрологический контроль может выполняться в рамках нормоконтроля, силами специально подготовленных нормоконтролеров. Замечания при метрологическом контроле имеют обязательный характер и подлежат устранению [4].

Метрологическая экспертиза конструкторской (КД) и технологической документации (ТД) занимает наибольший объем и вызывает значительные трудности у экспертов-метрологов. Рассмотрение вопросов и задач, решаемых при метрологической экспертизе технической документации, показывает, что они должны ориентироваться в большом объеме критериев и методов оценки, нормативных документов по вопросам метрологии, ЕСКД и ЕСТД.

В разных отраслях машиностроения основной объем составляют измерения геометрических характеристик (параметров). Анализ практики проведения МЭ машиностроительных чертежей и технологической документации показал наличие следующих типовых ошибок в КД и ТД [5, 6]:

$\rightarrow$ невозможность контроля детали или изделия в связи с особенностями конструкции, неправильным указанием допусков;

$\rightarrow$ неправильный выбор измерительных баз;

$\rightarrow$ необоснованный выбор средств измерений; применяются не соответствующие по точности средства измерений, что может привести к недостоверным результатам измерений и значительным потерям;

$\rightarrow$ нерационально задается большая номенклатура контролируемых параметров (общие допуски мало применяются);

$\rightarrow$ несоблюдение соотношения между допуском размера и геометрическими допусками (формы, ориентации, месторасположения и биения) и требованиям к шероховатости поверхности для разных уровней геометрической точности, в том числе:

$\checkmark$ допуски формы на ответственных поверхностях назначаются конструктором без увязки с допуском размера, без учета жесткости конструкции детали, определяемой соотношением $\mathrm{L} / 2 \mathrm{~d}$, или часто отсутствуют совсем;

$\checkmark$ допуски расположения задаются необоснованно, без учета условий работы или они неконтролепригодны ввиду неправильного выбора базового элемента (базовая поверхность выбирается малой длины по сравнению с контролируемой, имеет низкую точность);

$\checkmark$ при нормировании шероховатости поверхности не обеспечиваются минимально необходимые требования по параметру Ra, что может привести к дополнительной погрешности измерения.

Авторами предлагается методика проведения МЭ рабочей КД и ТД, разработанная на основе РМГ 63-2003 [4], требований ЕСКД и практики преподавания учебных модулей курса «Метрологическая экспертиза технической документации» на ведущих предприятиях Нижнего Новгорода. Методика включает основные задачи, критерии оценки и нормативные документы, необходимые для выполнения метрологической экспертизы разных видов технической документации $[5,6,7,8]$.

В настоящее время ошибки конструирования крайне трудно обнаружить автоматизированным путем. В то же время разработчик не всегда имеет возможность своевременно получить необходимую информацию по технологии изготовления, измерению и контролю деталей. Технологические и метрологические службы загружены своими задачами. В большинстве случаев отсутствуют актуализированные базы данных средств технологического оснащения (оборудования, режущего инструмента, оснастки и т.п.) и средств измерений и контроля, имеющихся на предприятии. Это объясняется отсутствием активных информационных связей между системами «конструктор», «технолог», «метролог».

Анализ возможностей современных CAD-систем показал, что они не обеспечивают конструкторскую, технологическую и метрологическую поддержку разработчика при проектировании деталей [9,10]. B CADсистемах есть встроенные библиотеки для выбора допусков размеров, формы, расположения поверхностей, параметров шероховатости. Конструктор выбирает допуски из предлагаемого системой списка, отклонения при этом проставляются автоматически. Но в системах отсутствует проверка взаимоувязки назначаемых разработчиком геометрических характеристик (параметров), проверка контролепригодности параметров и т.д. Все это приводит к ошибкам в рабочих чертежах, неправильному составлению технологии изготовления, к доработкам документации, потере времени при подготовке производства и снижению качества выпускаемых изделий.

При подготовке и реализации программы создания единого информационного пространства промышленности России «4.0 RU» [11] необходимо обеспечить и единую информационную среду между системами «конструктор», «технолог», «метролог». Конструкторская, технологическая и метрологическая информационная поддержка разработчика при проектировании изделий значительно облегчит 
труд проектировщика, метролога-эксперта, сократит затраты времени и повысит качество КД и ТД.

\section{ЛИТЕРАТУРА}

1. Федеральный закон Российской Федерации от 26 июня 2008 года № 102-ФЗ «Об обеспечении единства измерений» (с изм.).

2. ГОСТ 2.111-2013. Единая система конструкторской документации (ЕСКД). Нормоконтроль.

3. ГОСТ 14.206-73. Технологический контроль конструкторской документации.

4. РМГ 63-2003. ГСИ. Обеспечение эфрфективности измерений при управлении технологическими процессами. Метрологическая экспертиза технической документации.

5. Кайнова В.Н., Лебедев Г.И., Тесленко Е.В. Метрологическая экспертиза технической документации учебно-методическое пособие. - Н. Новгород: НГТУ, 2010. 40 с.

6. Кутяйкин В.Г., Кайнова В.Н., Зимина Е.В. [и др.]. Метрологическая экспертиза технической документации машиностроения: учебно-методическое пособие. - Н. Новгород: НГТУ, 2017. 340 с.

7. Зимина Е. В., Кайнова В.Н. Роль метрологической экспертизы технической документации в повышении проектного качества продукции // Труды НГТУ. Н. Новгород, 2015. № 4. С. 186-192.
8. Зимина Е.В., Кайнова В.Н., Кутяйкин В.Г. Метрологическая экспертиза конструкторской документации продукции машиностроения // Компетентность. 2015. № 7. С. 43-46.

9. Андреев В.В., Тесленко Е.В. Автоматическое формирование массива конструктивно-технологических признаков деталей интеллектуальной информационной системой // Вестник БГТУ им. В.Г. Шухова. 2010. № 3. С. 170-174.

10. Андреев В. В., Тесленко Е. В. Интеллектуальная информационная система технологического проектирования в CAD-системах // Научнотехнический вестник Поволжья. 2011. № 6. С. 90-92.

11. Стартовала программа создания единого цифрового пространства промышленности «4.0 ru» // СТАНКОИНСТРУМЕНТ. 2018. № 1 (010). С. 19.

\section{ЗИМИНА Елена Витальевна - \\ кандидат технических наук, доцент кафедры «Машиностроительные технологические комплек- сы», НГтУ им. Р.Е. Алексеева}

\section{КАЙНОВА Валентина Николаевна -}

кандидат технических наук, доцент кафедры «Теоретическая и прикладная механика»

нГтУ им. Р.Е.Алексеева

\section{НОВЫЕ КНИГИ ИЗДАТЕЛЬСТВА ТЕХНОСФЕРА»}

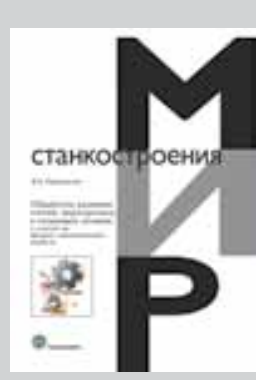

Цена 1210 руб.

\section{ОБРАБОТКА РЕЗАНИЕМ СТАЛЕЙ, ЖАРОПРОЧНЫХ И ТИТАНОВЫХ СПЛАВОВ С УЧЕТОМ ИХ ФИЗИКО- МЕХАНИЧЕСКИХ СВОЙСТВ}

\section{Paйхепьсон B.A.}

